Proc. Estonian Acad. Sci. Eng., 2001, 7, 1, 22-34

\title{
CHARACTERIZATION OF POWDER PARTICLE MORPHOLOGY
}

\author{
Valdek MIKLI ${ }^{\mathrm{a}}$, Helmo KÄERDI ${ }^{\mathrm{b}}$, Priit KULU ${ }^{\mathrm{c}}$, and Michal BESTERCI ${ }^{\mathrm{d}}$ \\ a Centre for Materials Research, Tallinn Technical University, Ehitajate tee 5, 19086 Tallinn, \\ Estonia; miku@staff.ttu.ee \\ b Department of Mathematics, Estonian Public Service Academy, Kase 61, 12012 Tallinn, \\ Estonia; helmo.kaerdi@sisekaitse.ee \\ c Department of Materials Technology, Tallinn Technical University, Ehitajate tee 5, 19086 \\ Tallinn, Estonia; pkulu@edu.ttu.ee \\ d Institute of Materials Research of the Slovak Academy of Sciences, Watsonova 47, 04353 \\ Košice, Slovakia; besterci@imrnov.sas4c.sk
}

Received 6 December 2000

\begin{abstract}
Technological properties of powders depend on their granulometry and particle morphology. Most of the image analysis methods provide only average size parameters (diameter, area, perimeter, etc.) which are often inadequate for characterizing the morphology of the particles. For particle abrasivity characterization, angularity factors are more sensitive. This paper studies different parameters for describing the hardmetal powder granulometry and morphology. The main aim is to find numerical descriptors for the shape factors that adequately characterize the hardmetal powders produced by the mechanical method - milling in a disintegrator. For the characterization of the powder particle morphology, irregularity parameter IP (relation of the diameters of the maximum inscribed and minimum circumscribed circles) suits best, taking into account the ellipticity and irregularity of the particle form. For describing the angularity of ground powders, the so-called "spike parameter - quadratic fit" can be used.
\end{abstract}

Key words: hardmetal powder, granulometry, morphology, shape factor, angularity

\section{INTRODUCTION}

Main characteristics of powders are the particle size (granulometry) and particle shape (morphology). Technological properties of powders (bulk density, flowability, surface area, etc.) as well as the potential areas of their application depend on these characteristics. Using powders for thermal spray, the preferable particle shape is spherical in order to have high flowability of powders and 
optimal conditions of particle melting and spraying. These are preconditions for producing high density and high wear resistant sprayed or melt coatings. Using hard powder in abrasive tools, particles must have high abrasivity (angularity). The same problem occurs with abrasive wear since the wear caused by abrasive grits depends on their size, shape, hardness, etc. The results of laboratory tests confirm that a direct correlation exists between the abrasive particle shape and the wear rate. Namely, the increase in particle angularity results in a significant increase of abrasive wear.

The granulometry of powders can be determined by different methods (sieve analysis, image analysis, laser analysis, etc.), but the question is how adequately they describe the powder granulometry. In $\left[{ }^{1}\right]$ we showed that the evaluation of coarse powder granulometry (particle size more than $50 \mu \mathrm{m}$ ) by means of sieve analysis guarantees sufficiently good results. The granulometry of the powder is adequately described by the modified Rosin-Rammler (Weibull) distribution function, and the method may be used to characterize powders produced by collision. Evaluation of the fine powder granulometry (with particle size less than $50 \mu \mathrm{m}$ ) is more difficult. The results of the sieve analysis do not describe adequately the powder granulometry. As shown in $\left[{ }^{2}\right]$, comparison of powder granulometry determined by sieve and laser analyses reveale considerably different results - the laser analysis provides finer granulometry of the powder. It shows that sieve analysis is inadequate and unsuitable for fine powder classification. Due to high speed and accuracy, particle evaluation by means of image analysis increases considerably the quality of the evaluation methods, particularly for fine powders $\left[{ }^{2}\right]$.

Size parameters (for example, average diameter, area or perimeter) describe a geometrical object independently of its shape. The morphology of a powder particle is characterized by description (spherical, angular, dendritic, dish-shaped, acircular) or quasi-quantitatively, for example, by means of geometrical shape parameters. The shape parameter characterizes mainly the shape, without considering the size. Qualitative descriptions of particle visual appearance, such as "rounded", "semi-angular" or "angular", have been used to classify and differentiate between various groups of abrasive particles. Several attempts have been made to characterize particle shape using various numerical descriptions $\left[{ }^{3-5}\right]$. The aim of this paper is to find new numerical descriptors for characterizing the hardmetal powders.

\section{METHODS OF CHARACTERIZING THE PARTICLE SHAPE}

To characterize particle shape, different shape factors are calculated. Often ellipticity parameters are used. Ellipticity can be effectively measured and calculated. To characterize ellipticity, aspect $A S$ is used $\left[{ }^{1,2}\right]$

$$
A S=a / b,
$$


where $a$ and $b$ are the axes of the Legendre ellipse (Fig. 1). The Legendre ellipse is an ellipse with the centre in the object's centroid and with the same geometrical moments up to the second order as the original object area. The Legendre ellipse is often used instead of the original object $\left[{ }^{1}\right]$. The shape factor, elongation $E L$, is defined as

$$
E L=\log _{2}(a / b)
$$

and dispersion $D P$ as

$$
D P=\log _{2}(\pi a b) .
$$

The relationship between $E L$ and $A S$ can be expressed as follows:

$$
\begin{gathered}
E L=\log _{2}(a / b)=\log _{2} A S=\log A S / \log 2, \\
A S=2^{E L} .
\end{gathered}
$$

The elongation of a circle is zero and of an ellipse with the ratio of axes $1: 2$ it is equal to one. Elongation grows for the ellipses with an increase in the ratio of the major and secondary axes (Fig. 2). Dispersion is a measure which allows one to evaluate differences in smoothness. It makes possible to compare smoothness of the evaluated object with the ideal ellipse: dispersion of an ellipse is zero and it grows with the increase of the object's roughness (Fig. 3).

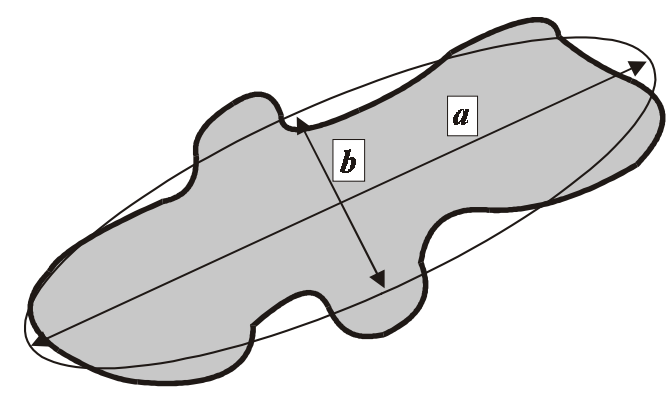

Fig. 1. Morphology study based on the Legendre ellipse.

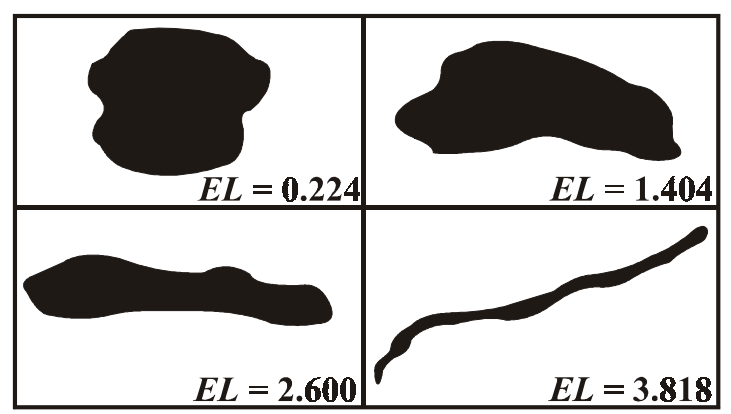

Fig. 2. Samples with different values of the elongation $E L$. 


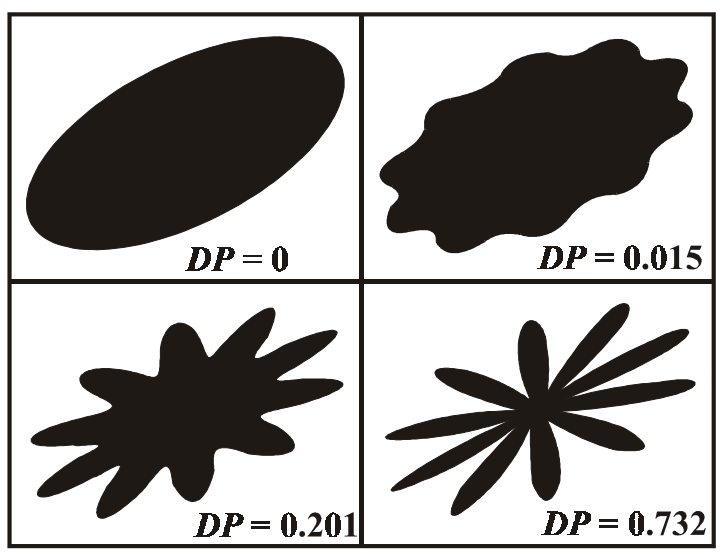

Fig. 3. Samples with different values of the dispersion $D P$.

Another well-known and often used characteristic for particle irregularity characterization is roundness of the object $R N$. If $P$ is the perimeter and $A$ is the area of the object, then roundness is defined as $\left[{ }^{1,3}\right]$

$$
R N=P^{2} / 4 \pi A .
$$

The roundness of a circle is equal to one. If the object's shape approaches a line segment, it approaches infinity. To characterize the roundness, sometimes shape factor $S F=1 / R N$ is used. The roundness factor proposed in $\left[{ }^{4}\right], R N F$, is defined by the relationship

$$
R N F=P / d_{A},
$$

where $d_{A}$ is the diameter of the circle with the same area as the particle (Fig. 4).

To evaluate the ellipticity and irregularity of the shape of the particle, in $\left.{ }^{5}\right]$ the so-called irregularity parameter $I P$ is defined

$$
I P=D / d,
$$

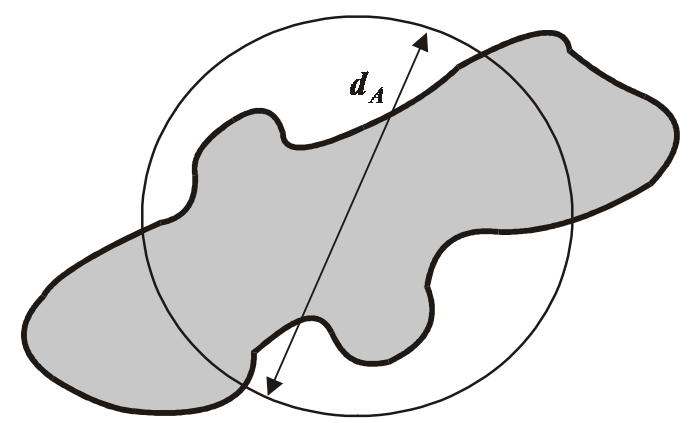

Fig. 4. Morphology study based on the circle with the same area as the particle. 
where $d$ and $D$ are the diameters of the maximum inscribed and minimum circumscribed circles, respectively (Fig. 5). As shown in [ $\left.{ }^{5}\right]$, IP can be applied both to elongated and irregular particles, but it does not allow to decide whether the particle is elongated or irregular.

A very important parameter of powder particles is their angularity. Several attempts have been made to characterize abrasive particle angularity using various numerical descriptors and to correlate particle shape with its ability to abrade or erode. For that $A S$ and $R N$ can be used, but as shown in $\left[{ }^{6}\right]$, they are not sufficiently sensitive to angularity. Investigating the influence of the shape on the erosion rate, in $\left.{ }^{7}\right]$ the ratio of the radius of the tip $r$ to the "mean" radius of the particle $R$ was used as the shape factor. Values of the shape factor $r / R$ are in the range from 1.0 (sphere) up to 2.3-2.7 (cast iron debris).

In $\left[{ }^{8,9}\right]$ the particle angularity was described by a numerical parameter called "spike parameter - linear fit" SP. A particle boundary is "walked" around with a fixed step, represented by a set of triangles with the height $h$ and apex angle $\theta$ (Fig. 6a). It has been assumed that the sharpness and size of these triangles are directly related to particle abrasivity. Spike value $S V$ is defined as

$$
S V=h \cos \frac{\theta}{2},
$$

and $S P$ is calculated as

$$
S P=\frac{1}{n} \sum \frac{1}{m} \sum \frac{S V_{\max }}{h_{\max }},
$$

where $m$ is the number of valid $S V$ for a given step size and $n$ is the number of different step sizes used. In this method, many thousands of triangles are to be calculated for each boundary in order to obtain $S P$.

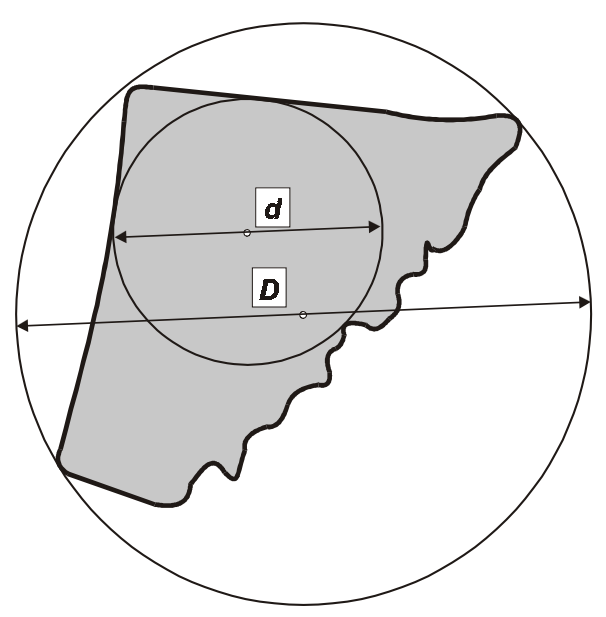

Fig. 5. Morphology study based on the maximum inscribed and minimum circumscribed circles. 


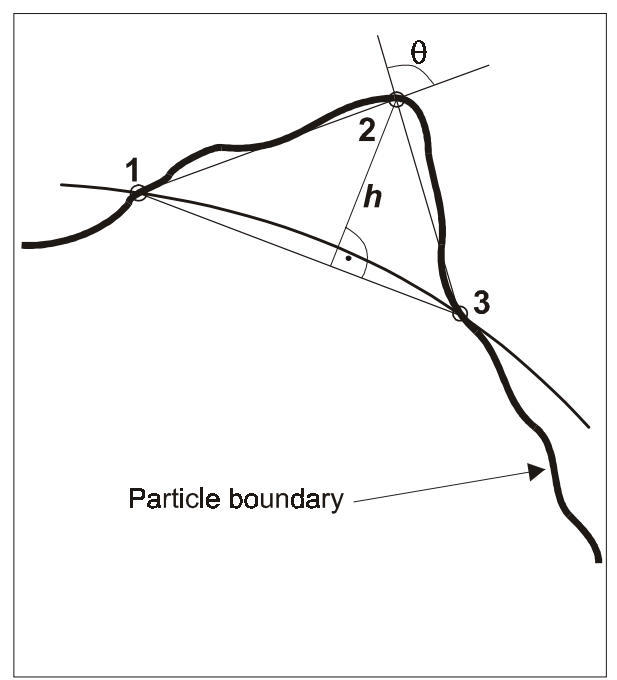

a.

Fig. 6. Schematic illustration of calculation methods of $S P$ by constructing triangles round the boundary (a) and of $S P Q$ based on fitting quadratic segments to protruding sections of the particle boundary (b).

A modified particle angularity parameter, called "spike parameter - quadratic fit" $S P Q$, was developed by the same authors to eliminate the deficiencies of the $S P$ method $\left[{ }^{9}\right]$. The parameter $S P Q$ takes into account only those spikes that are outside the circle with equal particle area centred over the particle centroid. The areas outside the circle, spikes, are regarded as areas of interest, while those inside the circle are omitted. For each protrusion outside the circle, i.e., spike, the local maximum radius is found and this point is treated as the spike's apex, as shown in Fig. 6b. The sides of the spike, which are between the points 1-2 and 2-3 are represented by fitting quadratic polynomial functions. Differentiating the polynomials at the point 2 yields the apex angle $\theta$ and the spike value $S V$, i.e., $S V=\cos (\theta / 2) . S P Q$ is calculated as

$$
S P Q=S V_{\mathrm{av}} .
$$

From $\left[{ }^{10}\right]$ it follows that $S P Q$ is very sensitive; for different abrasives of $+0.25-0.3 \mathrm{~mm}$ (glass, silica sand, garnet, quartz, alumina, $\mathrm{SiC}$ ) the value of $S P Q$ is in the range of $0.0231-0.6008$. The effects of the particle angularity on two-body abrasive rates are explained in $\left[{ }^{11}\right]$. 


\section{APPLICATION OF PARTICLE SHAPE PARAMETERS FOR CHARACTERIZING DISINTEGRATOR MILLED HARDMETAL POWDERS}

The technology of producing hardmetal powders from the used (recycled) WC-Co hardmetal consists of preliminary cyclic thermal treatment and mechanical size reduction - milling of pretreated particles by collision $\left[{ }^{12,13}\right]$. To obtain hardmetal powder with the predetermined granulometry, multistage milling (up to 16 times) was used (specific energies of milling are given in Table 1).

Table 1. Milling parameters (disintegrator DSL 160, velocities of rotors 8000/8000 rpm)

\begin{tabular}{c|c|c|c}
\hline $\begin{array}{c}\text { Multiplicity } \\
\text { of milling }\end{array}$ & $\begin{array}{c}\text { Specific milling energy, } \\
\mathrm{kJ} / \mathrm{kg}\end{array}$ & $\begin{array}{c}\text { Multiplicity } \\
\text { of milling }\end{array}$ & $\begin{array}{c}\text { Specific milling energy, } \\
\mathrm{kJ} / \mathrm{kg}\end{array}$ \\
\hline 1 & 12.4 & 9 & 111.6 \\
2 & 24.8 & 10 & 124.0 \\
3 & 37.2 & 11 & 136.4 \\
4 & 49.6 & 12 & 148.8 \\
5 & 62.0 & 13 & 161.2 \\
6 & 74.4 & 14 & 173.6 \\
7 & 86.8 & 15 & 186.0 \\
8 & 99.2 & 16 & 198.4
\end{tabular}

Granulometry and morphology studies of the powders were carried out using two methods:

a) optical microscope transmission method, to produce the projections of powder particles,

b) optical microscope reflection method, to obtain the images of the crosssection polish.

Particle shape depends on the duration of milling: with an increase of time, milling particle obtains smooth spherical shape. In Table 2, the results of milling WC-Co hardmetal in a disintegrator are given $\left[{ }^{12,13}\right]$. The shape factors $E L, D P$, and $R N$ were determined by two different image analysis systems: DIPS $\left[{ }^{14}\right]$ and Image-Pro Plus $\left.3.0{ }^{15}\right]$. Their dependence on the number of disintegration cycles is shown in Fig. 7.

The elongation measured with DIPS drops monotonically while with ImagePro it has a maximum 0.81 after 3 cycles. Generally, the values of the elongation vary only in a small range - maximum 0.82 corresponds to the ellipse with the axes ratio $7: 4$ and the minimum 0.51 to the axes ratio $7: 5$. The dependence of $D P$ on the multiplicity of milling is monotonous, i.e., particles become smoother after every disintegration cycle.

The value of $R N$ depends weakly on the multiplicity of milling and also on the method of image processing (Table 2, Fig. 7). 

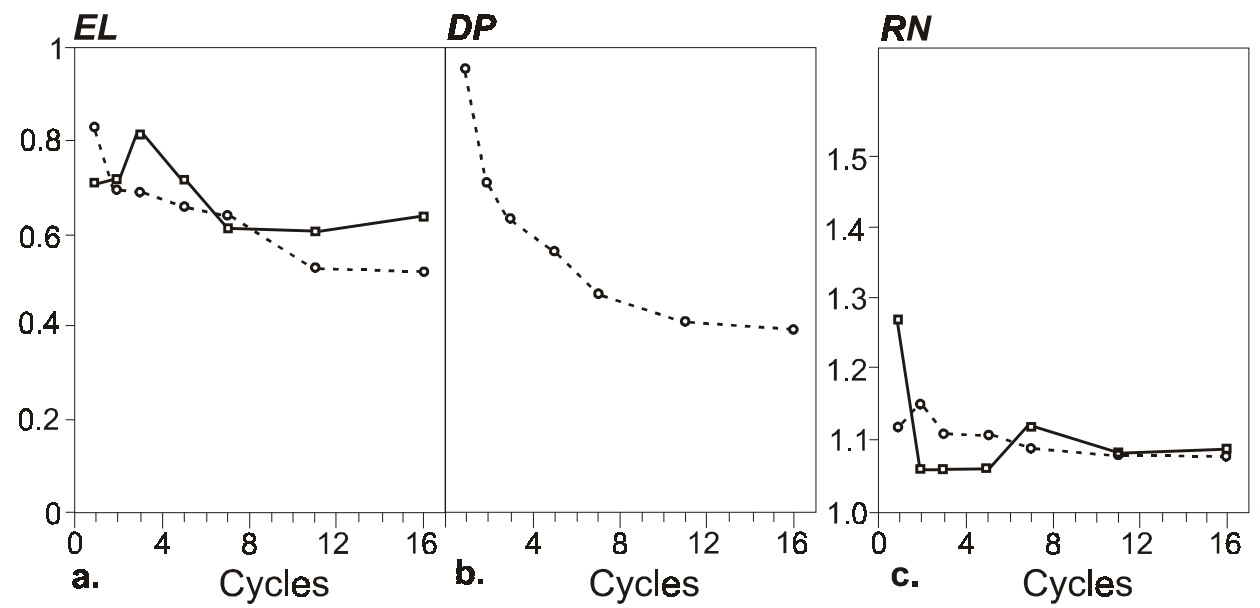

Fig. 7. Dependence of the average values of the elongation $E L$ (a), dispersion $D P$ (b) and roundness $R N$ (c) on the number of desintegration cycles (---- DIPS, - Image-Pro).

Table 2. Shape factors of milled WC-Co hardmetal powder particles

\begin{tabular}{c|l|c|c|c|c|c|c|c}
\hline \multirow{2}{*}{ Shape factor } & \multirow{2}{*}{$\begin{array}{c}\text { Method of } \\
\end{array}$} & \multicolumn{7}{|c}{ Multiplicity of milling } \\
\cline { 3 - 9 } & investigation & 1 & 2 & 3 & 5 & 7 & 11 & 16 \\
\hline \multirow{2}{*}{$A S$} & Image-Pro & 0.71 & 0.72 & 0.81 & 0.72 & 0.61 & 0.60 & 0.64 \\
$E L$ & DIPS & 0.82 & 0.69 & 0.68 & 0.65 & 0.63 & 0.52 & 0.51 \\
$D P$ & DIPS & 0.095 & 0.071 & 0.064 & 0.056 & 0.047 & 0.041 & 0.039 \\
$R N$ & Image-Pro & 1.27 & 1.06 & 1.06 & 1.06 & 1.12 & 1.08 & 1.09 \\
$R N$ & DIPS & 1.12 & 1.15 & 1.11 & 1.11 & 1.09 & 1.08 & 1.08
\end{tabular}

In Table 3, the shape factors of regular configurations are given in the order of increasing sharpness: circular, orthogonal, hexagonal, quadrangular, and triangular. As it follows from Table $3, I P$ is the most sensitive parameter and $R N F$ is the most insensitive one. Whereas $I P$ characterizes integrally both angularity and elongation, it does not allow to find separately angularity and elongation. In our case (mechanically milled hardmetal powder), where the powder particles are not elongated in shape (Fig. 8), IP is suitable for particle angularity characterization.

Table 3. Shape factors of particles of different form

\begin{tabular}{|c|c|c|c|c|c|}
\hline & \multicolumn{5}{|c|}{ Configuration } \\
\hline $\begin{array}{l}\text { Shape } \\
\text { factor }\end{array}$ & & & & & \\
\hline$R N$ & 1.0 & 1.055 & 1.103 & 1.273 & 1.654 \\
\hline$R N F$ & 1.0 & 1.027 & 1.050 & 1.128 & 1.286 \\
\hline$I P$ & 1.0 & 1.082 & 1.155 & 1.414 & 2.0 \\
\hline$S P Q$ & 0 & 0.383 & 0.5 & 0.707 & 0.866 \\
\hline
\end{tabular}



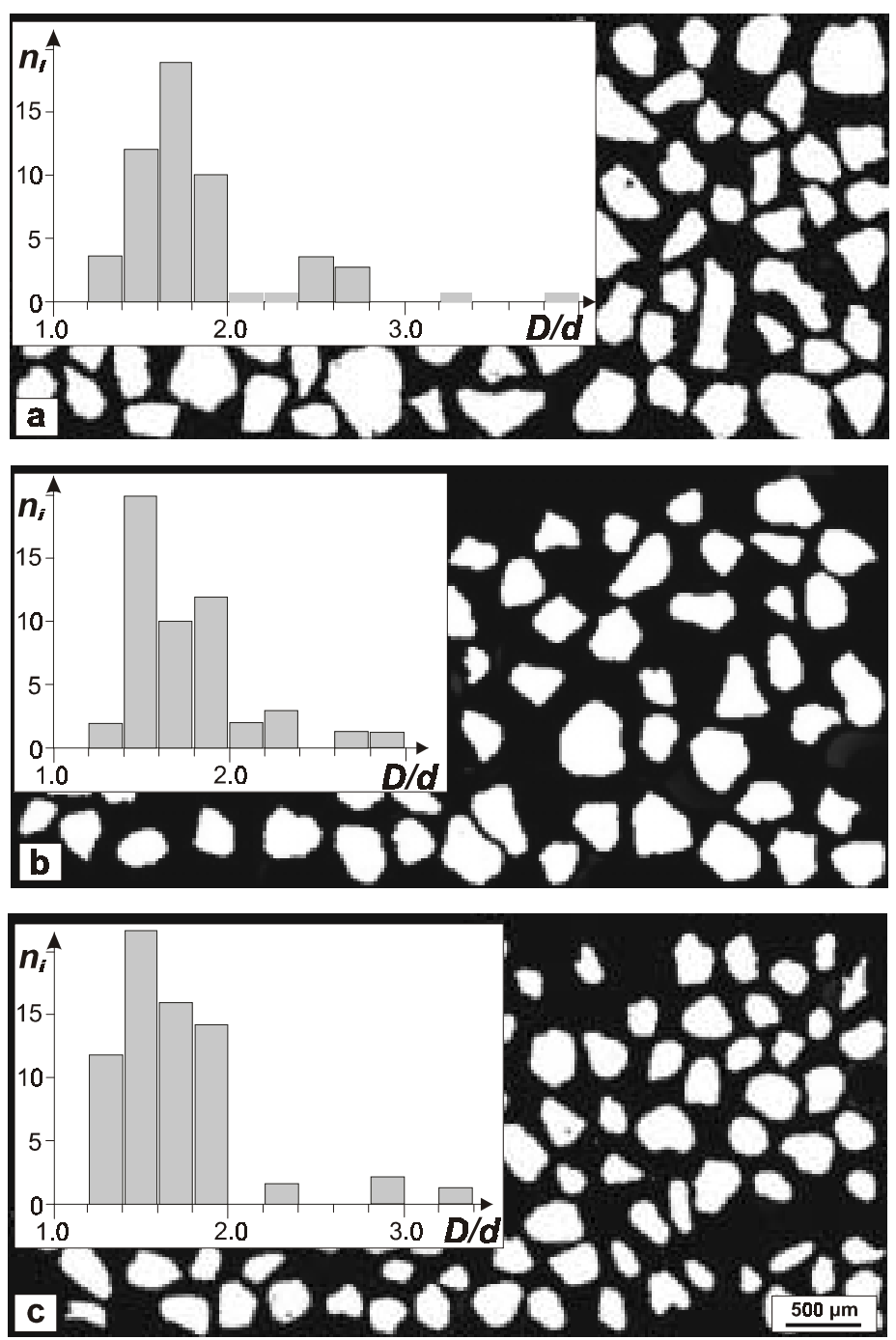

Fig. 8. Powder particle cross-sections and shape factor $I P$ histograms; multiplicity of milling: a -2 , $\mathrm{b}-5, \mathrm{c}-15$.

Using finely polished metallographic samples and photographs of crosssections of powder particles (Fig. 8), diameters $D$ and $d$ were measured and $I P$ was calculated. Results of calculation are given in Table 4 and on histograms in Fig. 8. Table 4 shows the results of multiple fine milling of hardmetal powder, preliminarily ground in a coarse grinder to the granulometry less than $2.5 \mathrm{~mm}$ (number of milling cycles up to 30-40). From Table 4 follows that the shape factor $D / d$ (both average and median) decreases during multiple milling only a little because of the preliminary multistage milling. Mode is not expressed 
particularly clearly - the maximums of the histograms (Fig. 8) are smoothed and remain more or less unchanged during the multistage milling. At the same time, an increase in the share of finer fraction $(D / d \leq 1.6)$ is observed in the multistage milling process. Figure 8 shows also that the two left columns of the histograms increase when the number of treatments increases.

Table 4. Characteristics of the disintegrated WC-Co hardmetal powder

\begin{tabular}{|c|c|c|c|c|c|c|}
\hline \multirow[t]{2}{*}{$D / d$} & \multicolumn{6}{|c|}{ Multiplicity of milling and number of particles } \\
\hline & Initial & 1 & 2 & 5 & 10 & 15 \\
\hline $1.00-1.20$ & 0 & 0 & 0 & 0 & 0 & 0 \\
\hline $1.21-1.40$ & 4 & 4 & 3 & 2 & 10 & 11 \\
\hline $1.41-1.60$ & 12 & 22 & 23 & 20 & 15 & 22 \\
\hline $1.61-1.80$ & 18 & 24 & 20 & 9 & 19 & 16 \\
\hline $1.81-2.00$ & 10 & 12 & 13 & 12 & 2 & 14 \\
\hline $2.01-2.20$ & 1 & 3 & 2 & 2 & 4 & 0 \\
\hline $2.21-2.40$ & 1 & 4 & 4 & 3 & 2 & 2 \\
\hline $2.41-2.60$ & 4 & 1 & 2 & 0 & 1 & 0 \\
\hline $2.61-2.80$ & 3 & 3 & 1 & 1 & 1 & 0 \\
\hline $2.81-3.00$ & 0 & 0 & 2 & 1 & 0 & 3 \\
\hline $3.01-3.20$ & 0 & 0 & 0 & 0 & 1 & 0 \\
\hline $3.21-3.40$ & 1 & 1 & 1 & 0 & 0 & 2 \\
\hline $3.41-3.60$ & 0 & 0 & 0 & 0 & 0 & 0 \\
\hline $3.61-3.80$ & 0 & 0 & 0 & 0 & 0 & 0 \\
\hline $3.81-4.00$ & 1 & 0 & 0 & 0 & 0 & 0 \\
\hline Total number of particles $n$ & 55 & 74 & 71 & 50 & 55 & 70 \\
\hline Average $\frac{D}{d}$ & 1.89 & 1.79 & 1.81 & 1.74 & 1.71 & 1.76 \\
\hline$\frac{D}{d} \leq 2.0, \%$ & 80 & 84 & 83 & 86 & 84 & 90 \\
\hline$\frac{D}{d} \leq 1.6, \%$ & 29 & 35 & 37 & 44 & 45 & 47 \\
\hline Standard deviation of $D / d$ & 0.51 & 0.36 & 0.40 & 0.34 & 0.38 & 0.44 \\
\hline Median of $\frac{D}{d}$ & 1.75 & 1.67 & 1.70 & 1.64 & 1.64 & 1.64 \\
\hline Mode of $\frac{D}{d}$ & 1.6 & 1.6 & 1.6 & 1.5 & 1.6 & 1.5 \\
\hline
\end{tabular}

Figure 9 shows the photographs of cross-sections of the analysed powder particles after 2, 5, and 15 times of milling. Table 5 presents changes in the parameter $S P Q$, characterizing the dependence of powder particle angularity on the number of milling cycles. It shows that the circularity of coarse fraction increases (parameter $S P Q$ decreases) with an increase of the number of milling 


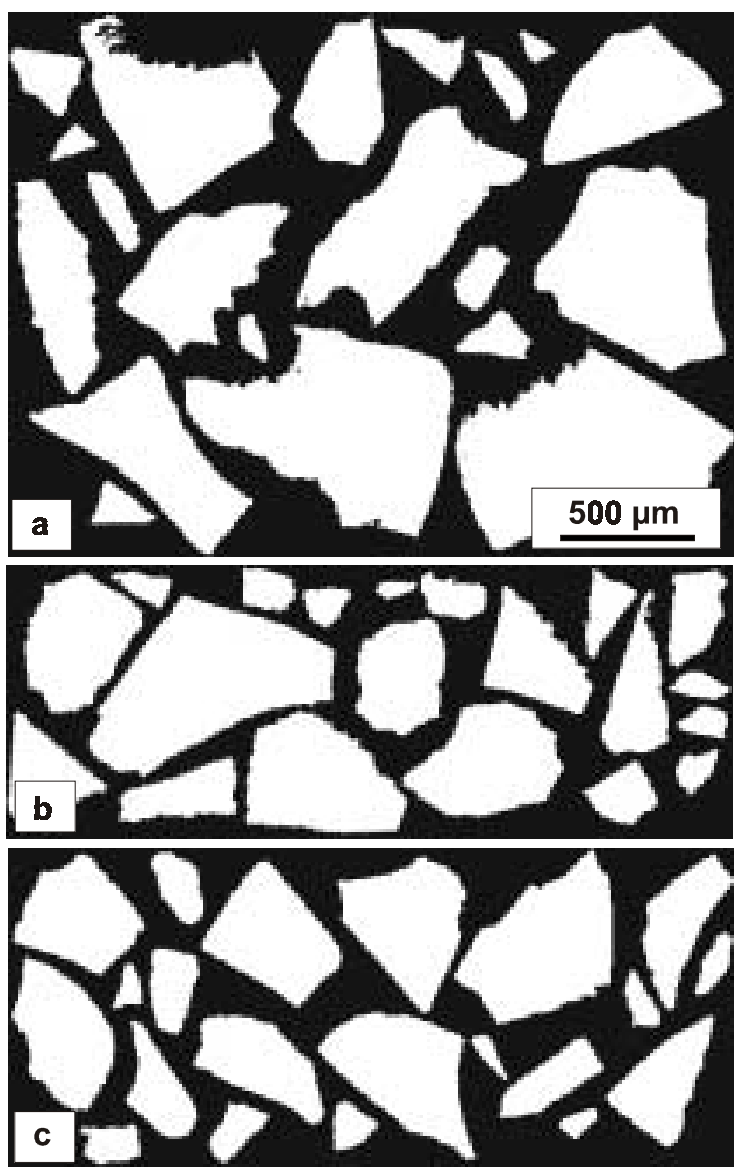

Fig. 9. Powder particle cross-sections; multiplicity of milling: $a-2, b-5, c-15$.

Table 5. Angularity parameter $S P Q$ of disintegrated WC-Co hardmetal powder

\begin{tabular}{l|c|c|c}
\hline \multirow{2}{*}{ Characterization of powder particles } & \multicolumn{3}{c}{ Multiplicity of milling } \\
\cline { 2 - 4 } & 2 & 5 & 15 \\
\hline Coarse fraction (particle size $0.3-1 \mathrm{~mm}, 10$ particles) & 0.652 & 0.585 & 0.522 \\
Fine fraction (particle size $0.1-0.3 \mathrm{~mm}, 10$ particles) & 0.645 & 0.648 & 0.630 \\
Average & 0.649 & 0.617 & 0.576
\end{tabular}

cycles. At the same time, $S P Q$ of particles of fine fraction does not decrease essentially. It means that fine fraction is the product of direct fracture of milling by collision. The circularity increases (angularity decreases) considerably by increasing number of milling cycles (Figs. 9, 10). 


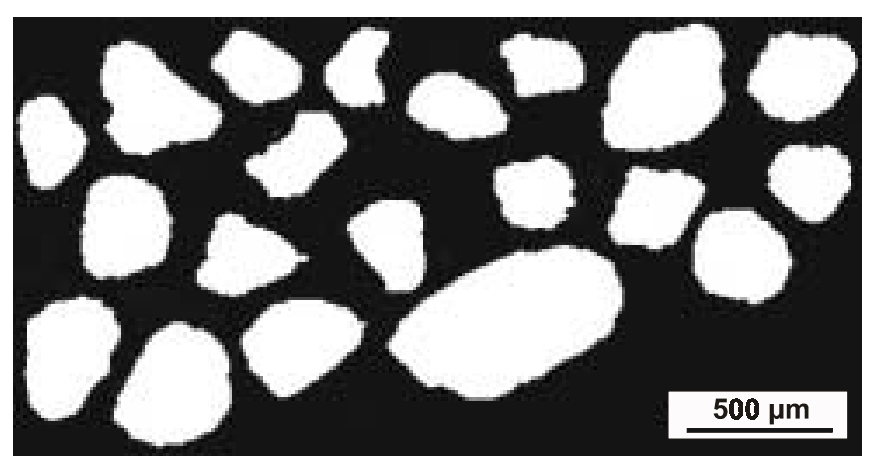

Fig. 10. Powder particle cross-sections milled about 45 to 50 times, $S P Q=0.258$.

\section{CONCLUSIONS}

1. The irregularity parameter $I P$ and spike parameter $S P Q$, the numerical descriptors of the shape factor that adequately characterize the particle morphology, may be used to characterize powders produced by mechanical methods. With an increase in the angularity of regular configuration (from circular to triangular), the values of $I P$ and $S P Q$ are in the range of 1.0-2.0 and $0-0.866$, respectively.

2. The parameter $S P Q$, studied for characterizing WC-Co hardmetal powders produced by multiple disintegrator milling, is a more sensitive characteristic of angularity than $I P$. For disintegrator ground powders, the values of $S P Q$ are in the range of $0.652-0.258$. At the same time, the average values of $I P$ that takes into account the ellipticity and irregularity of particles are in the range of 1.89 1.76.

3. The parameters $I P$ and $S P Q$ may be used to classify various groups of WC-Co hardmetal powders: powders for abrasives and powders for wear resistant composite coatings.

\section{ACKNOWLEDGEMENT}

The authors thank the Estonian Science Foundation for funding this research, grants No. 3404 and 4270.

\section{REFERENCES}

1. Kulu, P., Tümanok, A., Mikli, V., Käerdi, H., Kohutek, I., and Besterci, M. Possibilities of evaluation of powder particle granulometry and morphology by image analysis. Proc. Estonian Acad. Sci. Eng., 1998, 4, 3-17. 
2. Mikli, V., Kulu, P., Tümanok, A., and Käerdi, H. Comparative investigation of disintegrated WC-Co powders by the methods of sieving and image processing. In Proc. VII International Baltic Conference "Materials Engineering - 98”. Jurmala, Latvia, 1998, 9-13.

3. Saltykov, S. A. Stereometric Metallography. Metallurgiya, Moscow, 1976 (in Russian).

4. Sasov, A. Y. and Sokolov, V. N. Numerical processing of REM images. Izv. Acad. Nauk SSSR, Fiz., 1984, 184, 2389-2396 (in Russian).

5. Wojnar, L. Image Analysis Applications in Materials Engineering. CRC Press, Boca Raton, 1999.

6. Stachowiak, G. W. Numerical characterization of wear particle morphology and angularity of particles and surfaces. In New Directions in Tribology. Plenary and Invited Papers of the First World Tribology Congress (Hutchings, I. M., ed.). MEP Publications, London, 1997, 371-389.

7. Tadolder, J. Some correlation of the erosion of the technically pure metals. Tallinna Polütehnilise Instituudi Toimetised, 1966, 237A, 15-22 (in Russian).

8. Hamblin, M. G. and Stachowiak, G. W. A multi-scale measure of particle abrasivity. Wear, 1995, 185, 225-233.

9. Stachowiak, G. W. Numerical characterization of wear particle morphology and angularity of particles and surfaces. Tribology Int., 1998, 31, 139-157.

10. Stachowiak, G. B. and Stachowiak, G. W. The effects of particle characteristics of three-body abrasive wear. In Proc. 9th Nordic Symposium on Tribology NORDTRIB2000. Porvoo, 2000, 2, 434-443.

11. Stachowiak, G. W. Particle angularity and its relationship to abrasive and erosive wear. Wear, 2000, 241, 214-219.

12. Tümanok, A. and Kulu, P. Treatment of different materials by disintegrator systems. Proc. Estonian Acad. Sci. Eng., 1999, 5, 222-242.

13. Tümanok, A., Kulu, P., Mikli, V., and Käerdi, H. Technology and equipment for production of hardmetal powders from used hardmetal. In Proc. 2nd International DAAAM Conference. Tallinn, 2000, 197-200.

14. Drückmüller, M. and Heriban, P. Reference manual of the DIPS, v. 5.0. SOFO, Brno, 1992.

15. Image-Pro Plus 3.0. Start-up Guide. Media Cybernetics, USA, 1996.

\section{PULBRIOSAKESTE MORFOLOOGIA KIRJELDAMINE}

\section{Valdek MIKLI, Helmo KÄERDI, Priit KULU ja Michal BESTERCI}

Pulbrite tehnoloogilised omadused sõltuvad eelkõige nende granulomeetriast ja pulbriosakeste morfoloogiast. Osakeste suurust ja kuju iseloomustavad näitajad (diameeter, pindala, perimeeter jt.), mis on saadud kujutisanalüüsi tulemusel, ei kajasta sageli piisava täpsusega pulbriosakeste morfoloogiat, näiteks osakeste nurgelisust. Töös on vaadeldud pulbriosakeste morfoloogiat puudutavaid parameetreid, mis võimalikult adekvaatselt kirjeldavad desintegraatorjahvatusega saadud kõvasulampulbreid. Sobivaimad parameetrid kõvasulampulbri osakeste morfoloogia puhul on irregulaarsusnäitaja $I P$, mis integreeritult arvestab osakeste elliptilisust ja ebakorrapärasust, ning nurgelisuse näitaja $S P Q$. 